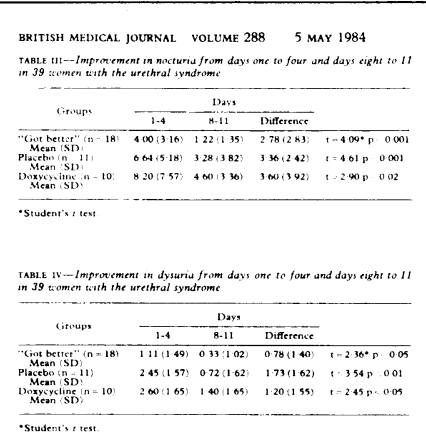

improved between days onc to four and days cight to 11 and there
were no significant differences between the groups

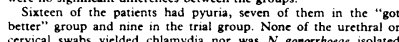

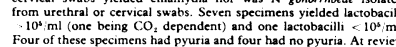

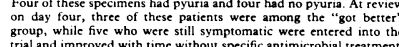

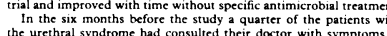

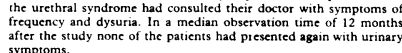

Discussion

Intensive efforts have been made to find a microbiological
causc for the urechral syndrome. Stamm $e t$ al, in a case control

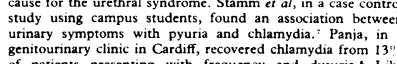

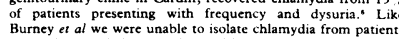

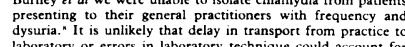

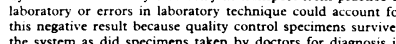

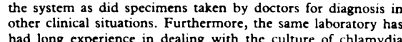

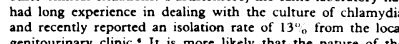

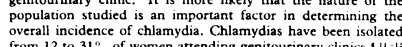

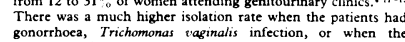

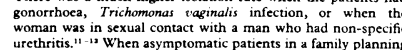

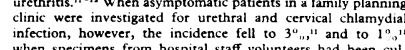

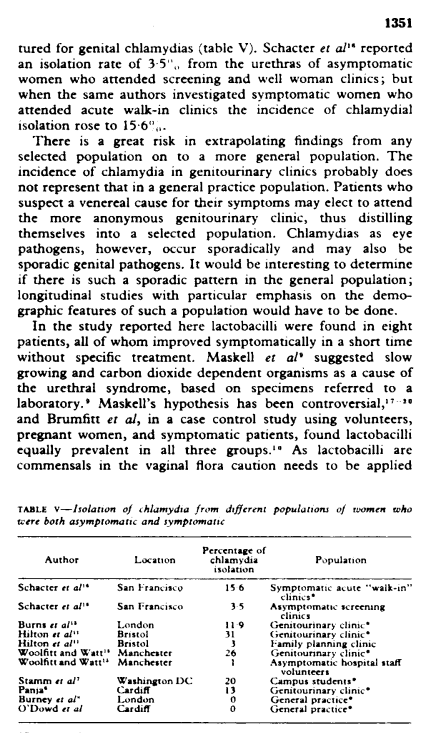

before attributing a pathogenic role to these fastidious organisms. Furthermore, app pying Kass's quantiatitive critiserion of $10^{\circ}$
organisms iml of urine is an unproved assumption that such a criterion applies to microaerophilic and anaerobic organisms.
Indeed, having such a quantitative cut off count may be un-
helpful in such infections which may well need to be assessed on their individual clinical merits with haboratory help. In this
study the findings of lactobacilli were too few to provide a

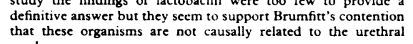
syndrome.
The findings of our study indicate that each monitored
episode of the urethral syndrome was short and self limiting. The numbers of patients admitted to the therapeutic crial were
small because nearly half the patients reported that they had small because nearly half the patients reported that they had
"got betrer" in the four day interval while awaiting the result
of the midstream urine specimen culture. Of the patients of the midstream urine specimen culture. Of the patients
admitted to the trial, there was no difference between those on doxycycline and those on placebo. Though the preconsultation
duration of the "got better" group - that is, those who said that they were better at revicu on day four-was statistically
significantly shorter than that of the trial group and though
the "gon berter" significantly shorter than that of the trial group and though
the "got better" group recocered morec quickly, this might still
be part of the same illness, of differing severity with some

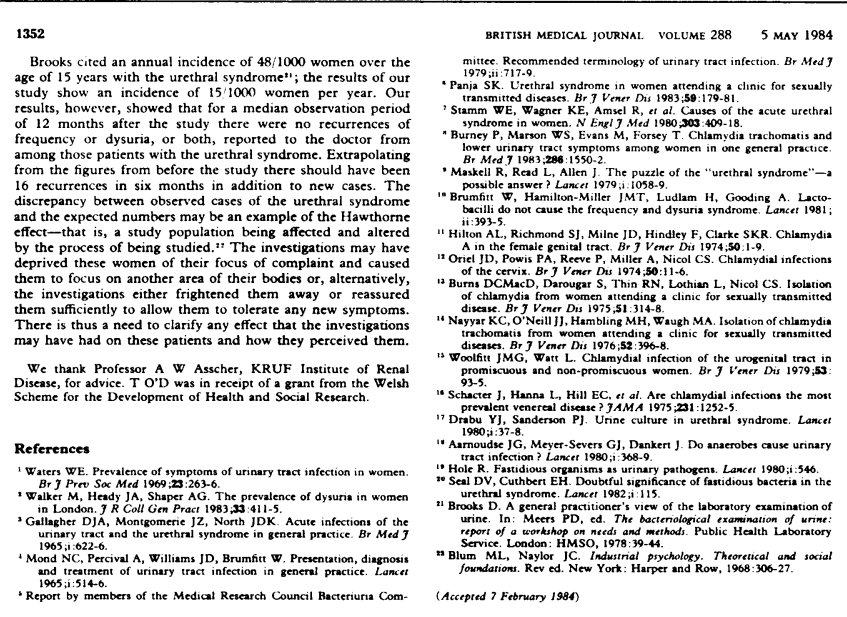

What Annoys Me Most

\section{Independence}

S R ILIFFE

What irritates me most about general practice? My
independence, of course! All other irritations are minor, by comparison.
Our independence shapes cach day's work. The convereed,
make shift premises that arc the norm of urban medicine are
evideses of

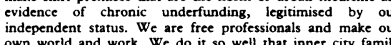

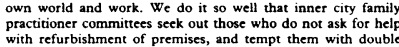
with returbishment of premises, and tempt them with double
size rants. Renovotion, conversion, and improvement are
events worth recording in free papers, as news, to show that

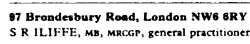

it is possible to haul onesself up by the boorstraps. In the urban
tandscape the ideal of the liberal professional disinitegrates

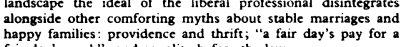
fair day's work"; ;and equality before the law.
We have a waiting list for A4 records, and gussetted Lloyd

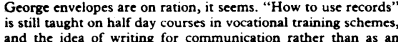

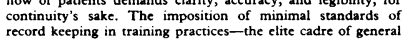

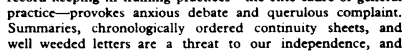

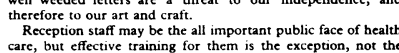

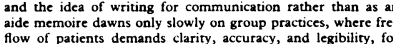

BRTIIS MEDICLL JOVRNAL VOLUME $288 \quad 5$ MAV 1984

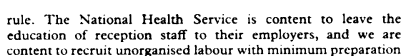

for work.
Endless, paperwork logging the quantity, but never the

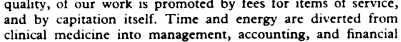

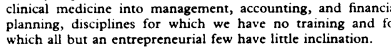

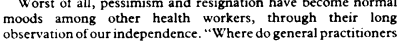
go in the afternon ? ? asked a consultant running a hypertension
clinic in a health centre empry of doctors save him. For him

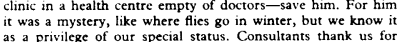

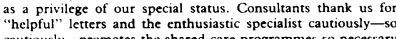

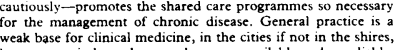

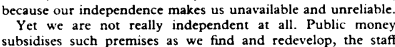
subsidises such premises as we find and redevelopp, the staff
we recrutit, and our growing expectations of larager inincomes,

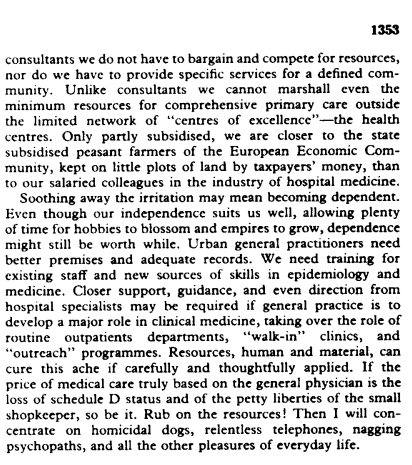

\title{
Minimum Standards for Training
}

\section{Minimum standards for training practices}

MIKE PRINGLE

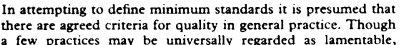
a few practices may be universally regarded as lamentable,
others are thought of as excellent by independent doctors. These

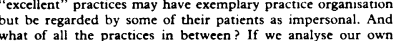

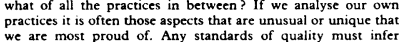

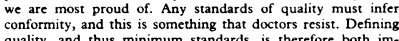

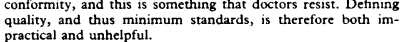
pracicical and unhelpful.
Discussing a set of reasonable expectations rather than minimum standards may be more worth while, but only with
certain provisos. A trainec is ilikely to spend his subsequen certain provisos. A traince is likely to spend his subsequent
career in no more than two practices, and his training should
prepare him specifically for the first of these. Because the

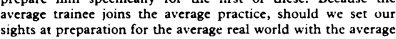

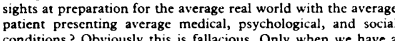

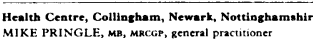

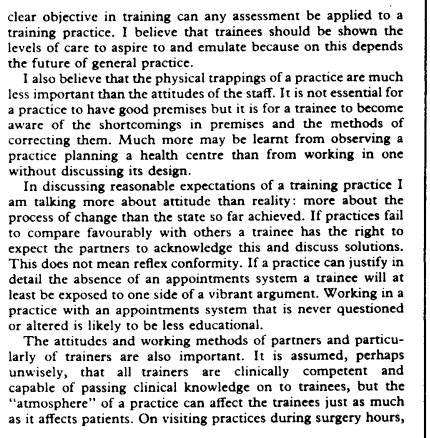

1354

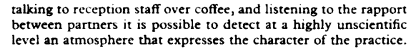

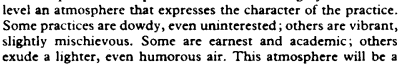

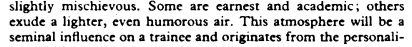
seminal influence on a trainec and originates from the persona
ties within the practice and how they interrelatef it is, of course
impossible

\section{Reasons ble expectations}

Given these obstacles to deffining even reasonable expectations in a training practice, somc broad arcas do nevertheless seem
reward examination. These are

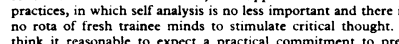
think it reasonablet to expect a practical commitment to pre-
ventive medicine a ancenatal and developmental clinis should

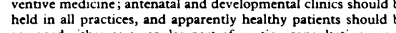
screened either as a regular part of routine consultations or
part of well woman and well man clinisis and geriatric screrening

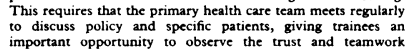

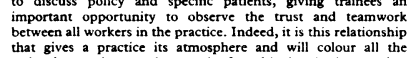

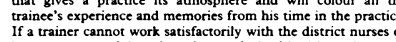

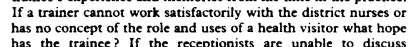

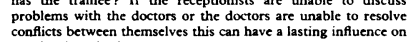

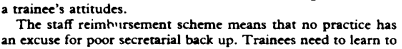

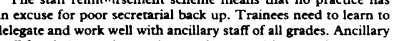

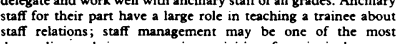

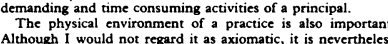

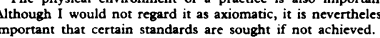

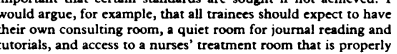

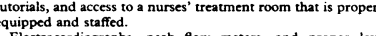

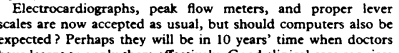

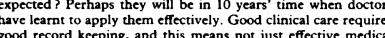

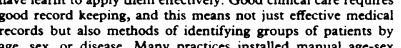

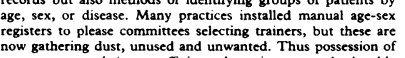

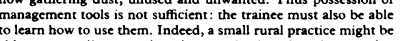
able to run a disease register in a notebook and get betrer value
from it than from an expensive and time consuming compurer.

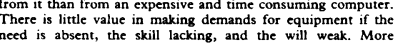
need is absent, the skill lacking, and the will weak. More
important is the engendering of an intellectual environment

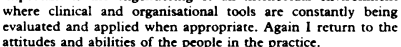

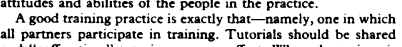

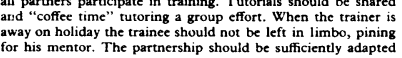

Brtrsh Mentcal Journal volume $288 \quad 5$ MAY 1984

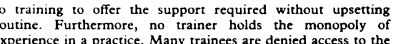

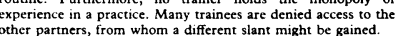
The counsel of perfection If all this sounds impossibly woolly and idealistic then
reffect hat histese points are exacty those hat should be the core

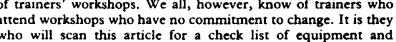

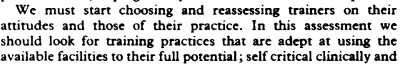

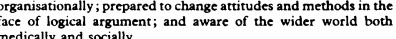

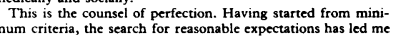

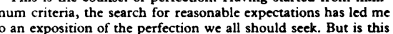
hot just the process chat the trainet should be encouraged to
underge? If the futurue of general practice is to be ensured through training then traineses muss be shown where present day
standards fail and taught the power of critical analysis necessary

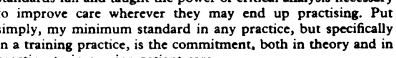
Diary of Urban Marks: 1880-1940

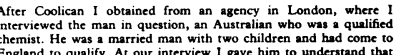

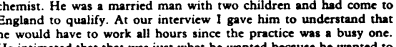

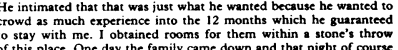

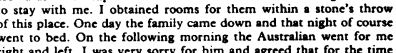

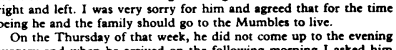

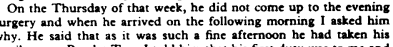

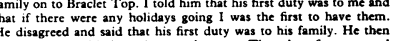

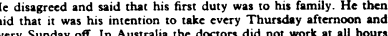

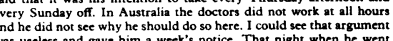

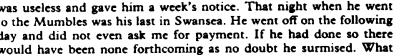

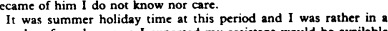

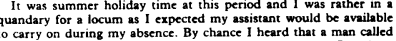

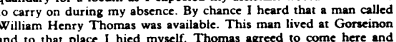

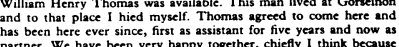

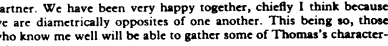

